\title{
Gallery of Honor - In Memoriam
}

\author{
Colaboradores honorários - In Memorian
}

Winston Bonetti Yoshida*

Over the last 3 years, the Jornal Vascular Brasileiro has lost some important people from its membership and editorial board. In view of the dynamics of the Jornal Vascular Brasileiro, these eminent colleagues' names had to be replaced with those of new members in order that the journal's work could carry on. However, this replacement will not pass unmarked by a sincere and deserved homage to these great names in the SBACV, who made considerable and significant contributions to the growth and prestige of our magazine. These colleagues take their places in the Jornal Vascular Brasileiro Gallery of Honor.

Professor Luiz Poli de Figueiredo graduated in Medicine from the medical faculty at the Santa Casa de Porto Alegre, RS, in 1983. He went on to do his residency in Cardiovascular Surgery at Professor Adib Jatene's service and an internship in Vascular Surgery in Barcelona, Spain. He completed both Masters and Doctorate at the Universidade Federal de São Paulo and undertook a Post- Doctoral research posting in Texas, United States, at Professor Coselli's service. Professor Figueiredo was a consultant for several research funding agencies and a peer reviewer for many high-prestige international magazines. He was a Specialty Editor for the Experimental Surgery department of the Jornal Vascular Brasileiro. He was a very talented researcher and Full Professor at the Department of Surgery at FMUSP and he made a huge contribution in the form of publications in highimpact journals. He made an enormous contribution to the growth and prestige of our Journal. Unfortunately, he passed away on the 1st of July in 2011.
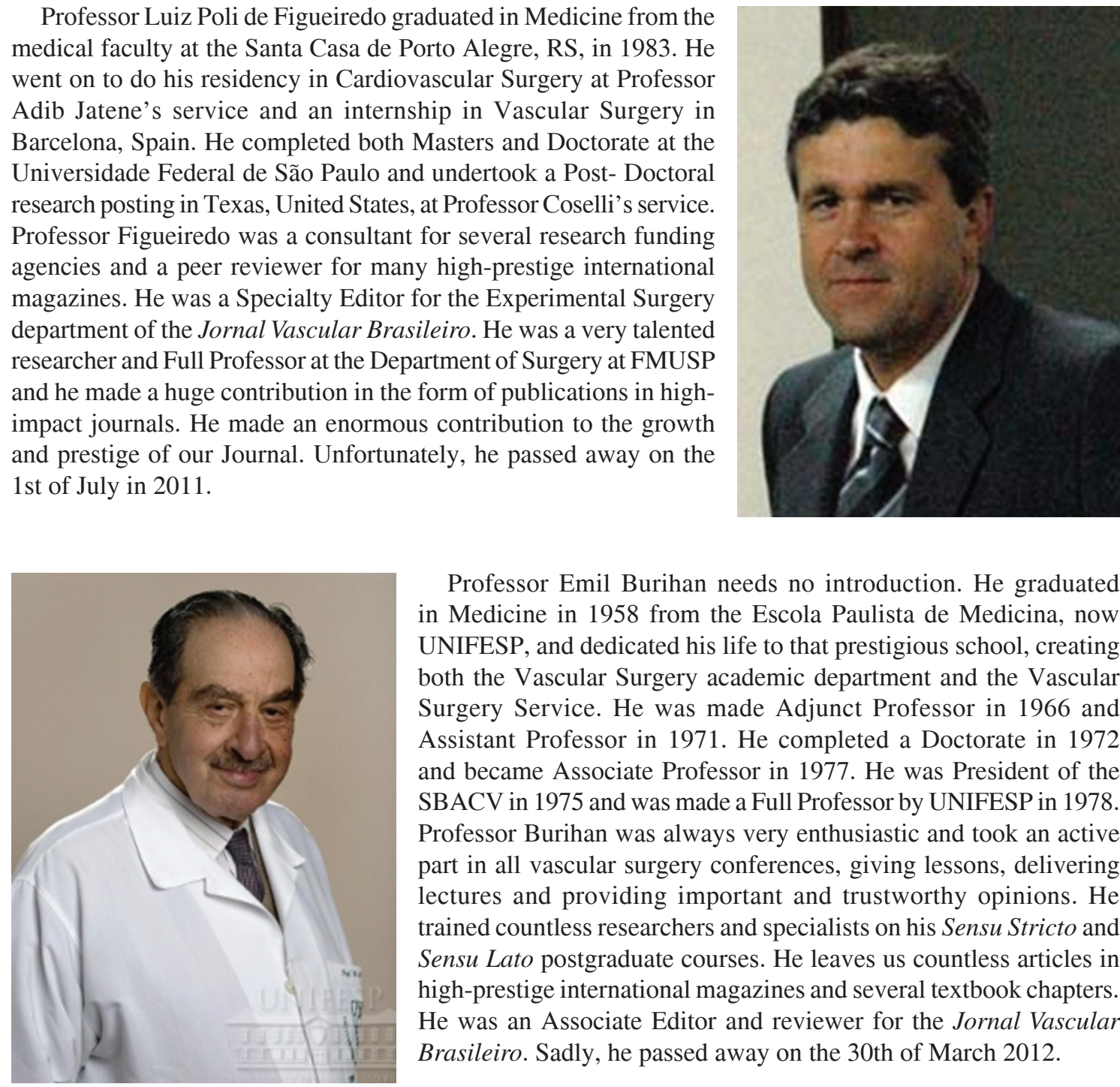

Professor Emil Burihan needs no introduction. He graduated in Medicine in 1958 from the Escola Paulista de Medicina, now UNIFESP, and dedicated his life to that prestigious school, creating both the Vascular Surgery academic department and the Vascular Surgery Service. He was made Adjunct Professor in 1966 and Assistant Professor in 1971. He completed a Doctorate in 1972 and became Associate Professor in 1977. He was President of the SBACV in 1975 and was made a Full Professor by UNIFESP in 1978. Professor Burihan was always very enthusiastic and took an active part in all vascular surgery conferences, giving lessons, delivering lectures and providing important and trustworthy opinions. He trained countless researchers and specialists on his Sensu Stricto and Sensu Lato postgraduate courses. He leaves us countless articles in high-prestige international magazines and several textbook chapters. He was an Associate Editor and reviewer for the Jornal Vascular Brasileiro. Sadly, he passed away on the 30th of March 2012. 


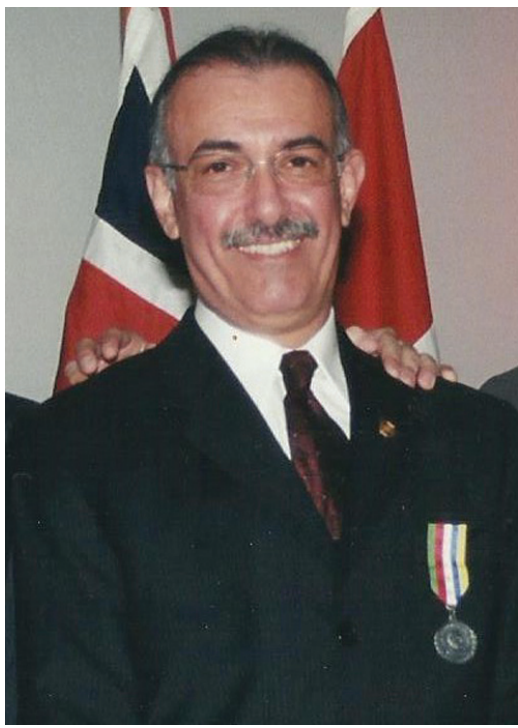

Professor Airton Delduque Frankini graduated in Medicine from the Fundação Faculdade Católica de Medicine de Porto Alegre in 1976, completing a Vascular Surgery Residency at the same institution in 1980. He completed his Masters in 1983 and his Doctorate in 1994, both at UNIFESP. He was Professor of vascular surgery at the Universidade Federal de Ciências da Saúde de Porto Alegre and was honored for his achievements by the Class of 2012. He held many positions in the Rio Grande do Sul chapter of the SBACV and on the National board and organized many scientific events in his town. He was elected President of the SBACV in 2006. He was a member of the Jornal Vascular Brasileiro Editorial Board, always punctual, writing critical reviews that were respectful and stimulating. On several occasions he temporarily stood in for me as Editor and never failed to complete his reviews for the Jornal Vascular Brasileiro, even when ill. Sadly, he passed away on 22nd of August 2012.

We therefore pay this simple homage to these important contributors to our journal and record our sense of loss at losing their collaborative efforts that made such a significant contribution to the growth and prestige of this periodical. 